\title{
Nucleophilic Displacement Reaction on Tosyl Cellulose by L- Methionine to the Synthesis of Novel Water-Soluble Cellulose Derivative and Its Antibacterial Activity
}

\author{
Lahcen El Hamdaoui $\mathbb{D}^{1},{ }^{1}$ Ahmed Talbaoui, ${ }^{2}$ and Mohammed El Moussaouiti ${ }^{1}$ \\ ${ }^{1}$ Laboratory of Materials, Nanotechnology and Environment, Center of Materials Sciences, Faculty of Sciences, Mohammed V \\ University in Rabat, Rabat, Morocco \\ ${ }^{2}$ Laboratory of Human Pathologies Biology, Department of Biology, Faculty of Sciences, Genomic Center of Human Pathologies, \\ Mohammed V University in Rabat, Rabat, Morocco
}

Correspondence should be addressed to Lahcen El Hamdaoui; la.elhamdaoui@gmail.com

Received 20 October 2020; Revised 17 January 2021; Accepted 1 February 2021; Published 15 February 2021

Academic Editor: Mehdi Salami-Kalajahi

Copyright (C) 2021 Lahcen El Hamdaoui et al. This is an open access article distributed under the Creative Commons Attribution License, which permits unrestricted use, distribution, and reproduction in any medium, provided the original work is properly cited.

\begin{abstract}
A novel ampholytic cellulose derivative, cellulose-L-methionine, has been synthesized by means of an esterification reaction of microcrystalline cellulose with tosyl chloride $(p-\mathrm{TsCl})$ in $\mathrm{DMAc} / \mathrm{LiCl}(8 \%)$ at $8^{\circ} \mathrm{C}$ that was followed by nucleophilic displacement $\left(\mathrm{S}_{\mathrm{N}}\right)$ of the tosyl group by the L-methionine amino acid. The resulting structure of cellulose-L-methionine has been characterized by elemental analysis (CHNSO), Fourier-transform infrared spectroscopy (FTIR), proton nuclear magnetic resonance $\left({ }^{1} \mathrm{H}-\mathrm{NMR}\right)$, and scanning electron microscopy (SEM). The antibacterial activity of the synthesized product was screened against Gram-positive and Gram-negative microbial strains such as Staphylococcus aureus, Escherichia coli, and Pseudomonas aeruginosa, by the agar well diffusion method, and compared with commercial antibiotics such as ampicillin and chloramphenicol. It was found that antibacterial experiment revealed excellent antibacterial activity of the cellulose-methionine with respect to a minimal inhibitory concentration (MIC) reference.
\end{abstract}

\section{Introduction}

Cellulose and its derivatives are of huge importance for various applications areas, food medical products, pharmaceutical industries, packaging, textile, etc., because of their very interesting chemical and physical properties, such as biodegradability, biocompatibility, bioactivity, and nontoxicity property $[1,2]$. Cellulose is the most abundant biopolymer in nature. Cellulose is insoluble in common organic solvents and in water [3]. This is due to the fact that the hydroxyl groups are responsible for the extensive hydrogen bonding network forming both intra- and intermolecular hydrogen bonding. However, special solvents were developed for the dissolved cellulose and for preparing a broad variety of cellulose derivatives by homogeneous chemical modification of the biopolymer [4-8]. By a chemical functionalization of cellulose, a wide variety of new macromolecules have been obtained [9-11]. For several years, great effort has been devoted to the synthesis of water-soluble cellulose derivative as promising biomaterials in high-end applications for drug delivery such as potential antibacterial activity $[12,13]$. For example, the synthesis of tosyl cellulose derivative intermediates through the tosylation of the primary hydroxyl group at C- 6 of cellulose has been reported since the tosyl group is a good electrophile and leaving group in nucleophilic displacement $\left(\mathrm{S}_{\mathrm{N}}\right)$ reactions or as protecting group in further reactions of the remaining free hydroxyl (-OH) groups [13-15]. In our previous work, we were able to synthesize tosyl cellulose with different degrees of substitution (DS) by reacting microcrystalline cellulose with $p$-tosyl chloride, and we have studied the effects of reaction parameters on DS by response surface methodology (RSM) [16]. Ampholytic biomaterials are semisynthesized biomacromolecular carrying both the ionic and cationic groups; they offer beneficial applications 
in drug delivery, protein separation, surfactants, and chelation with metal ions because of their structure specificity [17-20]. Several routs have been reported for the preparation of ampholytic cellulose such as the synthesis of cellulose sulfates functionalized with quaternary ammonium salt [21], synthesis of 6-deoxy N-sulfonated and N-carboxymethylated cellulose [22], and cellulose zwitterions [23].

Up to now, although researchers have synthesized some cellulose derivatives that are functionalized with the amino groups $[12,13,24,25]$, there are no published studies related to the synthesis of cellulose-L-methionine and its antibacterial activities to our knowledge.

In our concept, the key reaction is the nucleophilic displacement $\left(\mathrm{S}_{\mathrm{N}}\right)$ reaction of the tosyl cellulose by $\mathrm{L}$ methionine to synthesize new water-soluble ampholytic cellulose derivative with interesting molecular structure and properties, cellulose-L-methionine, and evaluated its antibacterial activities against a Gram-positive and Gram-negative microbial strains such as Escherichia coli, Pseudomonas aeruginosa, Staphylococcus aureus, and Streptococcus fasciens. The tosyl cellulose with DS $\approx 1$ was chosen as an intermediate to yield new water-soluble ampholytic cellulose by $\mathrm{S}_{\mathrm{N}}$. The reaction proceeds homogeneously in DMF at $80^{\circ} \mathrm{C}$ for $24 \mathrm{~h}$. The chemical structure and properties of the synthesized product were characterized by elemental analyses, Fouriertransform infrared spectroscopy (FTIR), proton nuclear magnetic resonance $\left({ }^{1} \mathrm{H}-\mathrm{NMR}\right)$, and scanning electron microscopy (SEM).

\section{Experimental Part}

2.1. Materials and Reagents. Microcrystalline cellulose commercial (Powder Aldrich Chemical) with a degree of polymerization $\mathrm{DP}=280$ was used as a starting polymer. $N, N$-Dimethylacetamide (DMAc), anhydrous lithium chloride ( $\mathrm{LiCl}$ ), tosyl chloride ( $p$-TsCl), $N, N$-dimethylformamide (DMF), L-methionine, potassium hydroxide ( $\mathrm{KOH})$, ethanol (EtOH), and triethylamine (TEA) were purchased from Sigma-Aldrich and were used without further purification.

2.2. Microorganisms and Inoculum Preparation. The tested microorganisms included the following bacteria: Escherichia coli ATCC 4157, Pseudomonas aeruginosa ATCC 27853, Staphylococcus aureus ATCC 25923, and Streptococcus fasciens 29212.

All pathogenic microorganisms isolated from patients were stored at the culture collection of the Biology Department (Microtech Unity) at the Faculty of Science, Rabat, Morocco. They were maintained in brain heart infusion $(\mathrm{BHI})$ at $-80^{\circ} \mathrm{C}$. Prior to the experiment, cultures were prepared by subculturing $1 \mathrm{~mL}$ of each culture stock in $9 \mathrm{~mL}$ of BHI broth.

\subsection{Methods of Material Analysis}

2.3.1. Spectroscopic Measurements. The apparatus used for infrared spectroscopy characterization is a Bruker Tensor 70 , which operates in transmittance mode. This apparatus is equipped with a Globar source that emits radiation in the region of midinfrared and of a DLaTGS detector. The acqui-

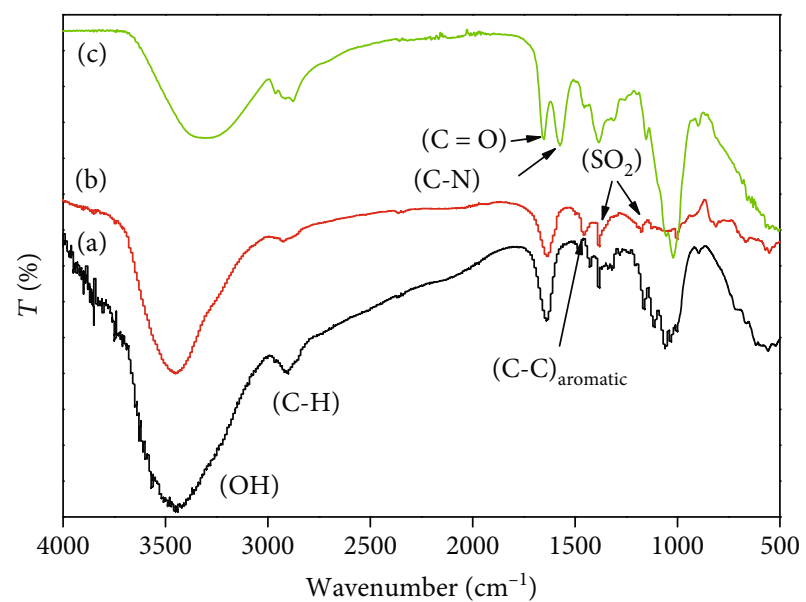

FIgURE 1: Infrared spectrum of MCC (a), tosyl cellulose (b), and cellulose-L-methionine (c).

sition is between 4000 and $400 \mathrm{~cm}^{-1}$ in wavenumber. The number of scans is of 20 with a resolution of $4 \mathrm{~cm}^{-1}$. Infrared spectrum was recorded from a sample in solid form prepared as pellets to $1 \%$ by weight of product dispersed in $\mathrm{KBr}$.

Nuclear magnetic resonance (NMR) spectra were recorded on a Bruker Advance $300 \mathrm{MHz}$ spectrometer with 16 scans for ${ }^{1} \mathrm{H}-\mathrm{NMR}$ at $25^{\circ} \mathrm{C}$ in $\mathrm{D}_{2} \mathrm{O}$ or DMSO and a sample concentration of $30 \mathrm{mg} / \mathrm{mL}$. The chemical shifts $(\delta)$ were expressed as part per million (ppm) against tetramethylsilane (TMS) as internal reference.

2.3.2. Scanning Electron Microscopy (SEM) Analysis. The surface morphology of the microcrystalline cellulose and the tosyl cellulose was analyzed by scanning electron microscopy (SEM), using a FEI Quanta 200 microscope. The samples were air dried for $24 \mathrm{~h}$ before imaging and were coated with a carbon layer to increase their conductivity. The images of samples were obtained using an accelerating voltage of $30 \mathrm{kV}$.

2.3.3. Elemental Analysis. Elemental analysis was performed by Euro EA - CHNSO Elemental Analyzer.

2.4. Typical Cellulose Dissolution Process in DMAc/LiCl Solvent System. In brief, $0.5 \mathrm{~g}$ of oven-dried microcrystalline cellulose $(3.08 \mathrm{mmol})$ was added to $20 \mathrm{~mL}$ of DMAc and the suspension was heated at $130^{\circ} \mathrm{C}$ for $2 \mathrm{~h}$. The resulted slurry was cooled down to $100^{\circ} \mathrm{C}$, and $1.6 \mathrm{~g}$ of anhydrous $\mathrm{LiCl}$ (8\%) was added to the mixture with stirring while cooling down the mixture at room temperature. The stirring was continued until the complete dissolution of cellulose within a few hours.

2.5. Synthesis of Tosyl Cellulose. Tosyl cellulose was prepared according to literature [26].

In brief, 2 mol eq. of TEA (43.12 mmol, $5.82 \mathrm{~mL}$ ) diluted in $10 \mathrm{~mL}$ of DMAc was added to the cellulose/DMAc/LiCl solution with stirring at room temperature. Afterwards, the reaction temperature was adjusted to $8^{\circ} \mathrm{C}$ and a solution of tosyl chloride ( $p$-TsCl) ( $7 \mathrm{moleq} ., 21.56 \mathrm{mmol}, 4.12 \mathrm{~g}$ ) in $25 \mathrm{~mL}$ of DMAc was added dropwise over $45 \mathrm{~min}$. The reaction mixture was kept stirring for additional $24 \mathrm{~h}$ at $8^{\circ} \mathrm{C}$. The 


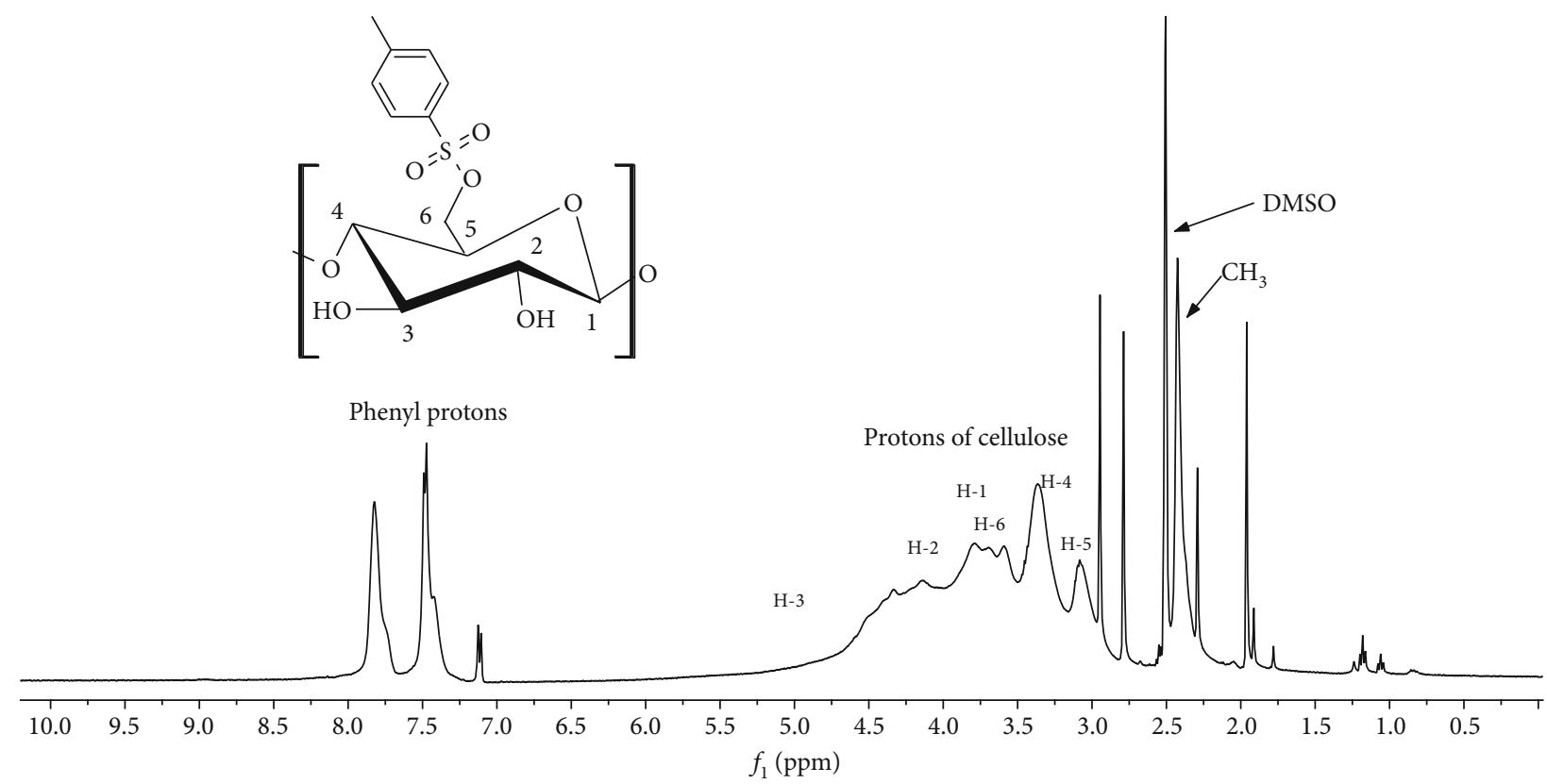

(a)

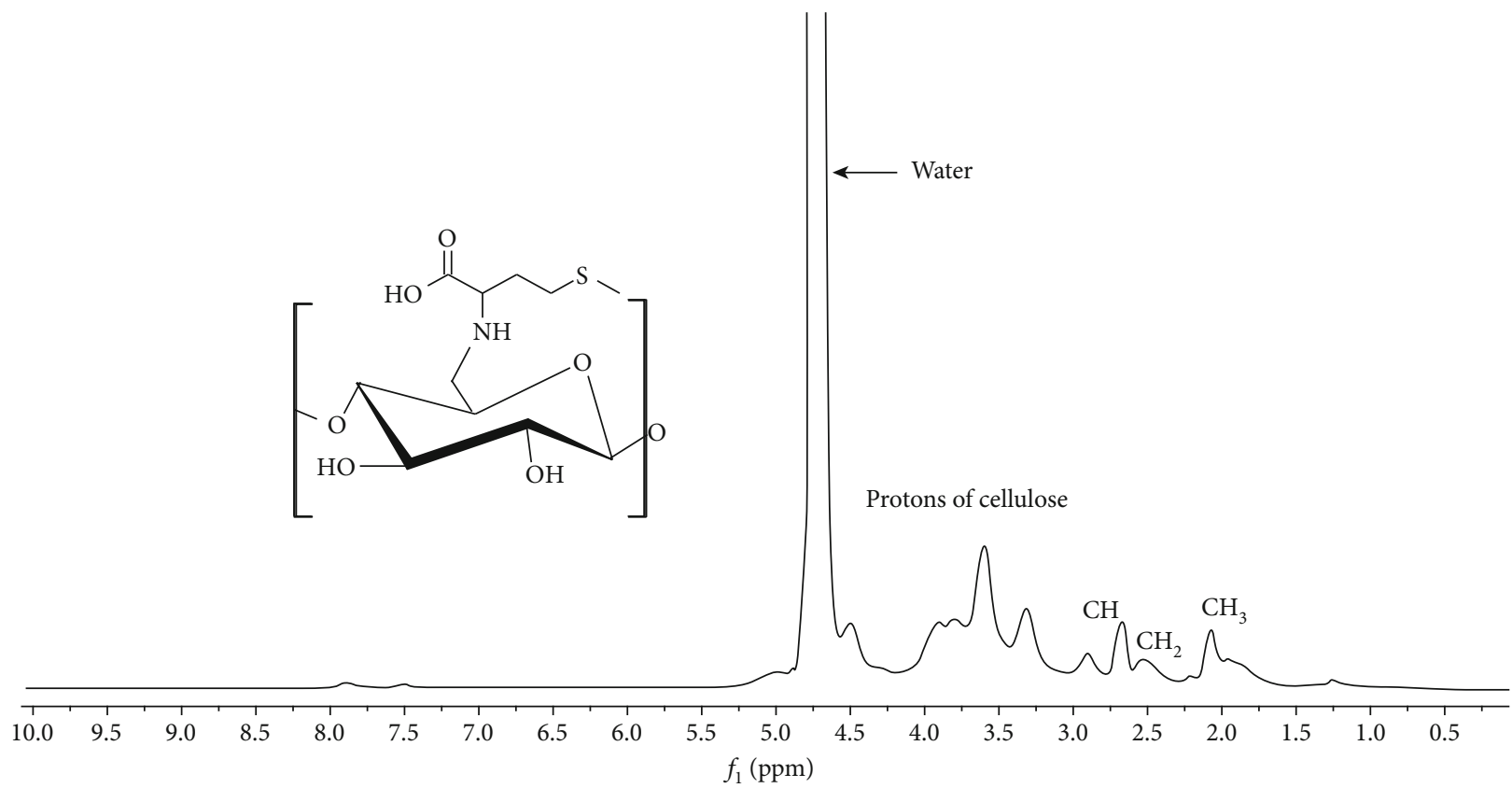

(b)

Figure 2: ${ }^{1} \mathrm{H}-\mathrm{NMR}$ for tosyl cellulose (a) and cellulose-L-methionine (b) derivative.

mixture was poured slowly into $500 \mathrm{~mL}$ of ice-cold water. The precipitate was filtered off, washed with about $500 \mathrm{~mL}$ of distilled water, and then washed with $500 \mathrm{~mL}$ of ethanol. The obtained product was dried at $40^{\circ} \mathrm{C}$ in oven for $12 \mathrm{~h}$ (yield: $81 \%$; elemental analysis for tosyl cellulose: $\mathrm{C}=45.23$, $\mathrm{H}=5.11, \mathrm{~N}=0.038$, and $\mathrm{S}=10.22$ ). The degree of substitution $(\mathrm{DS} \approx 1)$ in tosyl cellulose was determined from the sulfur content determined by the elemental analysis [27].

FTIR $\left(\mathrm{KBr}, v / \mathrm{cm}^{-1}\right)$ is as follows: $3459(v \mathrm{OH}), 2924(v \mathrm{C}-$ $\mathrm{H}), 1500,1456\left(v \mathrm{C}-\mathrm{C}_{\text {arom }}\right), 1370\left(v_{\mathrm{as}} \mathrm{SO}_{2}\right), 1172\left(v_{\mathrm{s}} \mathrm{SO}_{2}\right)$, $1116(\mathrm{C}-\mathrm{O}-\mathrm{C})$, and $813\left(v \mathrm{C}-\mathrm{H}_{\text {arom }}\right) \mathrm{cm}^{-1}$ (see Figure 1$)$.
${ }^{1} \mathrm{H}-\mathrm{NMR}$ (DMSO- $\left.\mathrm{d}_{6}\right)$ is as follows: $\delta 2.43\left(p-\mathrm{CH}_{3}\right), \delta 3.3-5$ (cellulose backbone), and $\delta 7.12-7.82 \mathrm{ppm}$ (tosyl cellulose) (see Figure 2).

2.6. Synthesis of Cellulose-L-Methionine. $200 \mathrm{mg}$ of tosyl cellulose $(0.63 \mathrm{mmol})$ with $\mathrm{DS} \approx 1$ was dissolved in $3 \mathrm{~mL}$ of hot $\operatorname{DMF}\left(S_{1}\right)$. Then, $3 \mathrm{moleq}$. (1.89 mmol, $\left.282 \mathrm{mg}\right)$ of the Lmethionine amino acid was dissolved in $3 \mathrm{~mL}$ of potassium hydroxide solution (10\%) and added dropwise over $60 \mathrm{~min}$ to $S_{1}$. The reaction mixture was then stirred and heated to $80^{\circ} \mathrm{C}$ for $24 \mathrm{~h}$. The product was isolated by precipitation of 


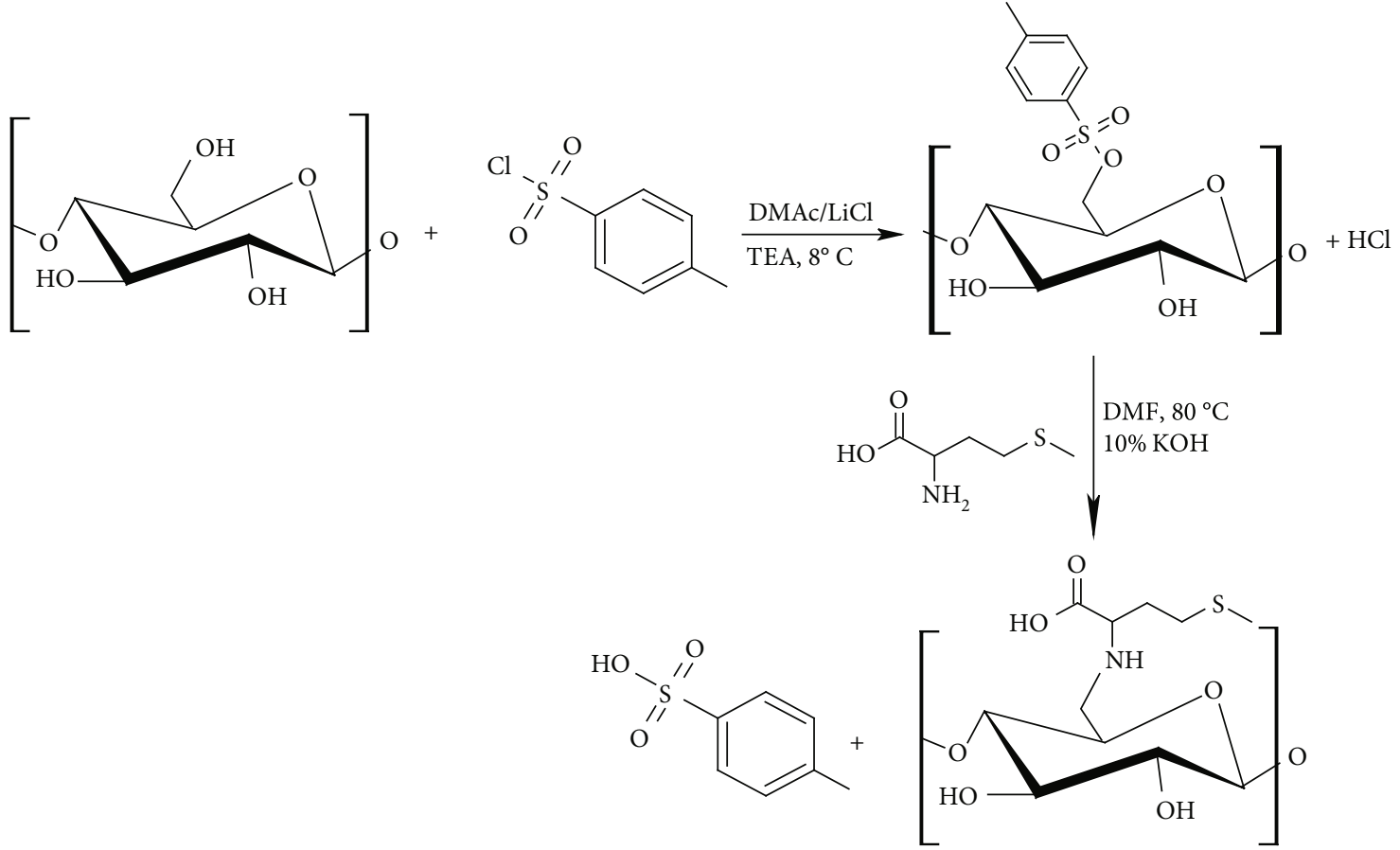

FIgURE 3: Reaction scheme for the synthesis of cellulose-L-methionine.

the reaction mixture into $100 \mathrm{~mL}$ of ethanol. The crude solid product was filtered off and washed several times with $100 \mathrm{~mL}$ of ethanol. The obtained product was oven dried at $40^{\circ} \mathrm{C}$.

Elemental analysis for cellulose-L-methionine is as follows: $\mathrm{C}=47.31, \mathrm{H}=6.18, \mathrm{~N}=3.23$, and $\mathrm{S}=5.79$.

FTIR $\left(\mathrm{KBr}, v / \mathrm{cm}^{-1}\right)$ is as follows: $3333(v \mathrm{OH}), 2920(v \mathrm{C}-$ $\mathrm{H}), 1654(v \mathrm{C}=\mathrm{O}), 1574\left(v \mathrm{C}-\mathrm{N}_{\mathrm{str}}\right)$, and $1023\left(\mathrm{C}-\mathrm{O}_{\text {str }}\right) \mathrm{cm}^{-1}$ (see Figure 1).

${ }^{1} \mathrm{H}-\mathrm{NMR}\left(\mathrm{D}_{2} \mathrm{O}\right)$ is as follows: $\delta 2.06,2.51$, and $2.67 \mathrm{ppm}$ $\left(\mathrm{CH}_{3}, \mathrm{CH}_{2}\right.$, and $\mathrm{CH}$ of L-methionine amino acid, respectively) and $\delta 3.3-5 \mathrm{ppm}$ (protons of cellulose backbone) (see Figure 2).

2.7. Agar Disc Diffusion Method. The agar disc diffusion method (ADD) was employed for the determination of antibacterial activities of the tested products as described previously. The principle of this technique is to estimate the bacteriostatic activity of antibacterial agents by measuring the growth inhibition zone of germs around wells. It is mostly used in a preliminary step to further study because it provides access to essentially qualitative results. The test samples were first dissolved in distilled water (DW), which did not affect the microbial growth.

Briefly, the test was performed in sterile petri plates containing medium agar. $30 \mathrm{~mL}$ of sterilized medium was poured into sterile petri plates. After solidification, $100 \mu \mathrm{L}$ of fresh cultures of bacteria species (one microorganism per petri plate). Sterile filter paper disc $(6 \mathrm{~mm}$ in diameter) was impregnated with $6 \mu \mathrm{L}$ of the test samples $(40 \mathrm{mg} / \mathrm{mL})$. All plates were sealed with sterile laboratory films to avoid eventual evaporation of the test samples and then incubated at $37^{\circ} \mathrm{C}$ for $24 \mathrm{~h}$. The diameter of inhi- bition zone was measured in millimeters. In addition, the antibacterial activity of the cellulose-L-methionine sample on Escherichia coli, Pseudomonas aeruginosa, Staphylococcus aureus, and Streptococcus fasciens bacteria was compared with the commercially available antibiotics. The antibiotic discs such as ampicillin and chloramphenicol were placed on the surface of the plates. Distilled water was used as a negative control. The plates were incubated at $37^{\circ} \mathrm{C}$ for $24 \mathrm{~h}$ after incubation. The diameter of inhibition zone was measured in $\mathrm{mm}$ and was recorded $[28,29]$.

2.8. Determination of the Minimum Inhibition Concentration (MIC). We tested six (6) serial concentrations of the high active products at concentrations 40,20, 10, 5, 2.5, and $1.25 \mathrm{mg} / \mathrm{mL}$, diluted in BHI broth. For MIC assessed, $5 \mathrm{~mL}$ of culture medium was inoculated with $0.1 \mathrm{~mL}$ of bacteria species. The MIC is the lowest concentration of samples, for which no growth was detected for $24 \mathrm{~h}$ at $37^{\circ} \mathrm{C}$.

\section{Results and Discussion}

3.1. Nucleophilic Substitution of Tosyl Cellulose with LMethionine Amino Acid. The tosyl cellulose derivative was synthesized by esterification of the hydroxyl groups of the microcrystalline cellulose chains with tosyl chloride. The reaction was carried out homogeneously in $\mathrm{DMAc} / \mathrm{LiCl}$ (8\%) solvent system at $8^{\circ} \mathrm{C}$ for $24 \mathrm{~h}$ in the presence of a strong base such as triethylamine (TEA). The tosyl cellulose with $\mathrm{DS} \approx 1$ so obtained was used as an intermediate to introduce additional amino acid into C-6. This new cellulose derivative was prepared by nucleophilic substitution $\left(\mathrm{S}_{\mathrm{N}}\right)$ reaction of the tosyl group; we have chosen $\mathrm{DS} \approx 1$ to avoid double steric effects of both the tosyl groups at C-2 and C-3 and the 


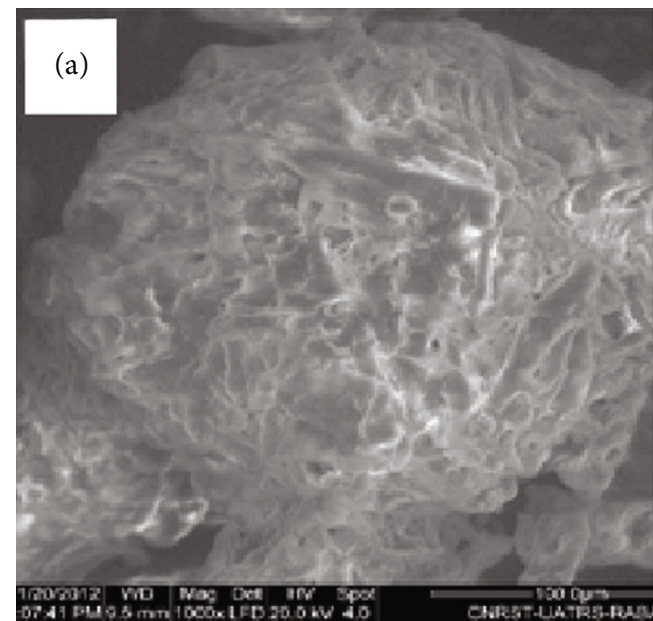

(a)

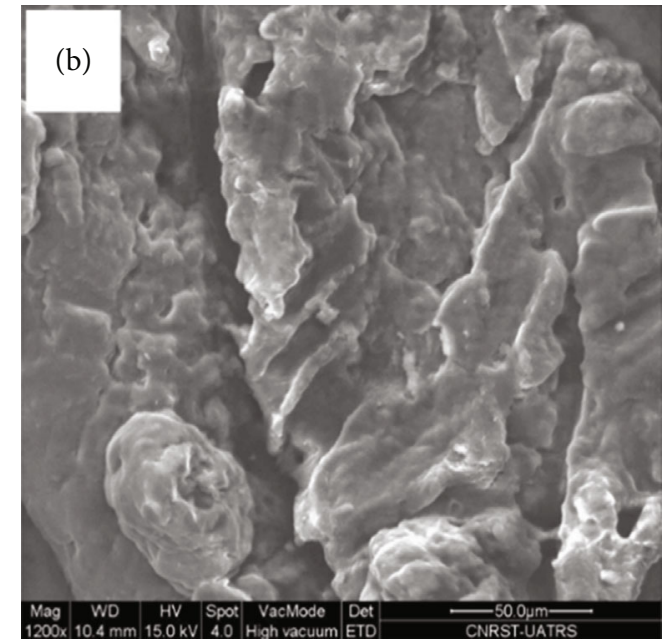

(b)

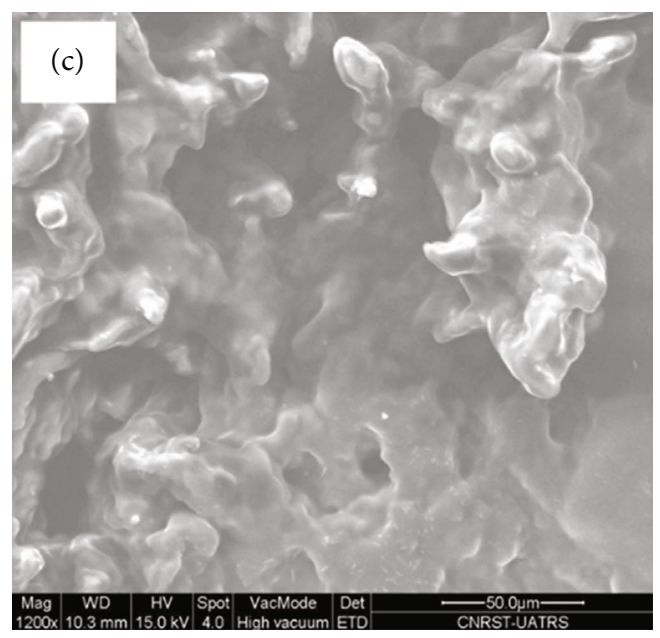

(c)

FIGURE 4: SEM microphotographs of MCC (a), tosyl cellulose (b), and cellulose-L-methionine derivative (c) (magnification: $\times 1200$ ).

glucose ring against nucleophilic attack of the tosyl group. The reaction process for the synthesis of cellulose-Lmethionine is shown in Figure 3.

\subsection{Characterization of Samples}

3.2.1. FTIR Spectroscopy. FTIR spectra of the MCC (a), tosyl cellulose (b), and cellulose-L-methionine (c) are shown in Figure 1. It can be seen that spectrum of tosyl cellulose provides a clear evidence of tosylation by showing the presence of some important peaks at $813 \mathrm{~cm}^{-1}$ for aromatic ring (C$\mathrm{H})$ stretching, $1116 \mathrm{~cm}^{-1}$ for (C-O-C) asymmetric stretching, and ring asymmetric stretching for cellulose. The absorption peaks at 1172 and $1370 \mathrm{~cm}^{-1}$ correspond, respectively, to $\left(\mathrm{SO}_{2}\right)$ group symmetric and asymmetric stretching, 1500 and $1456 \mathrm{~cm}^{-1}$ for aromatic (C-C) stretching, $3459 \mathrm{~cm}^{-1}$ for group $(\mathrm{OH})$ stretching of cellulose, and $2924 \mathrm{~cm}^{-1}$ for $(\mathrm{C}$ $\mathrm{H})$ cellulose. As expected, the infrared spectrum (c) of the new product, cellulose-L-methionine, showed neither asymmetric nor the symmetric valence vibrations of the $\left(\mathrm{SO}_{2}\right)$ group at $1172 \mathrm{~cm}^{-1}$ and at $1370 \mathrm{~cm}^{-1}$, which suggests its complete displacement by the L-methionine amino acid derivative. Furthermore, this disappearance of the tosyl group occurs with a concomitant appearance of a new strong absorption band around 1654 and $1574 \mathrm{~cm}^{-1}$ characteristic of the carboxylic group $(\mathrm{C}=\mathrm{O})$ and $\mathrm{C}-\mathrm{N}_{\text {str }}$ bend, respectively. Based on the FTIR results, it can be concluded that the reactions of nucleophilic substitution of tosyl cellulose with Lmethionine amino acid have been successful.

3.2.2. Elemental Analysis. The elemental composition of tosyl cellulose (TC) and cellulose-L-methionine was determined by microanalytical elemental analyses. The elemental analysis revealed that the S\% in tosyl cellulose was 10.22 and it was negligible in MCC, but it was 5.79 in cellulose-Lmethionine. Similarly, the N\% in both MCC and TC were 0.006 and 0.038 which increase upon the coupling of the amino acid to be $3.23 \%$ in cellulose-L-methionine.

3.2.3. NMR Spectroscopy. Comparing the ${ }^{1} \mathrm{H}-\mathrm{NMR}$ spectra of the synthesized samples, tosyl cellulose (a) and cellulose-Lmethionine derivative (b) in Figure 2 gave a clear-cut 


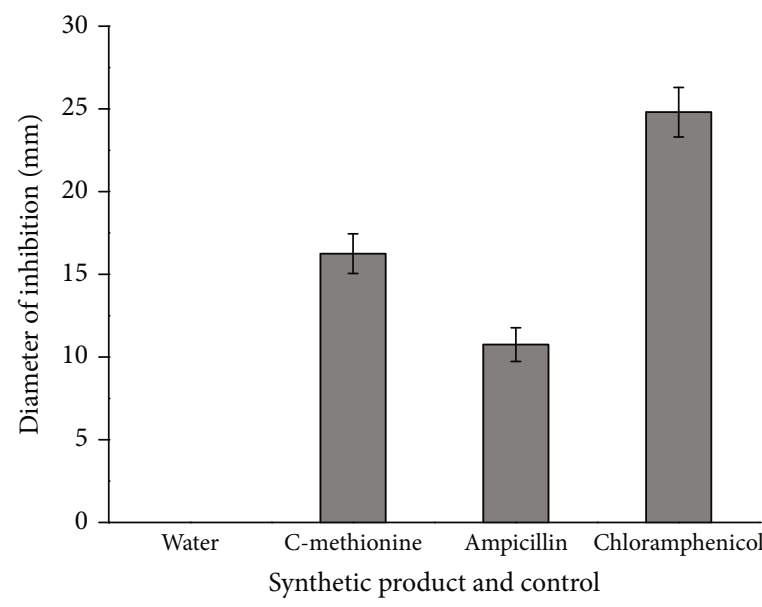

Escherichia coli

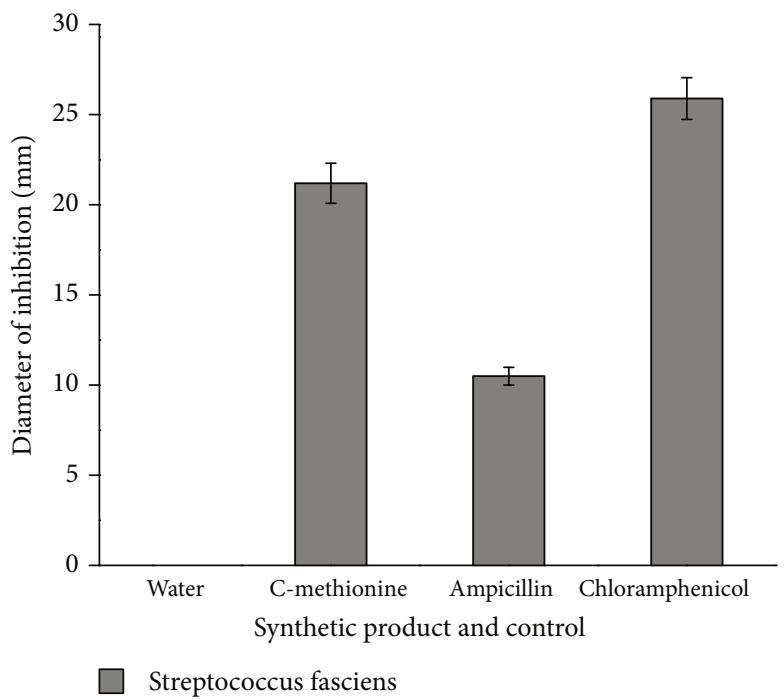

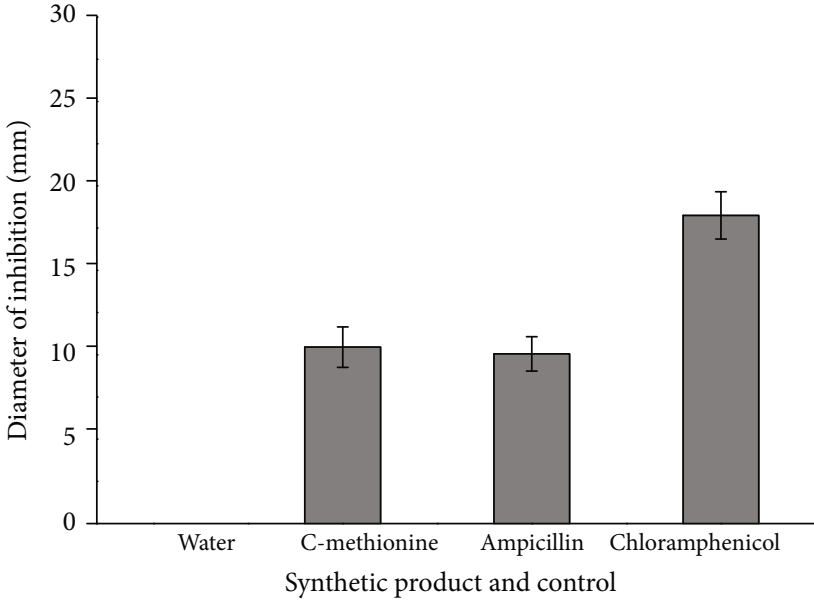

Pseudomonas aeruginosa

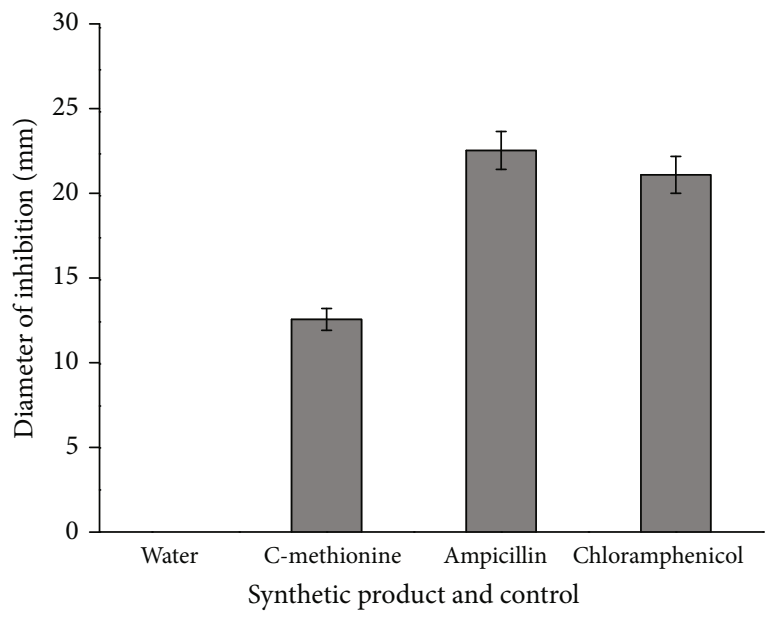

Staphylococcus aureus

FIgURE 5: Antibacterial activity of cellulose-L-methionine (C-methionine) and commercial antibiotics ampicillin and chloramphenicol against bacteria Escherichia coli, Pseudomonas aeruginosa, Staphylococcus aureus, and Streptococcus fasciens.

confirmation of the nucleophilic substitution reaction. The ${ }^{1} \mathrm{H}-\mathrm{NMR}$ results clearly suggest the success of tosylation reaction of microcrystalline cellulose by existence of phenyl protons at $\delta 7.12-7.82 \mathrm{ppm}$, methyl protons $\left(p-\mathrm{CH}_{3}\right)$ of the tosyl group at $\delta 2.43 \mathrm{ppm}$, and protons of cellulose backbone at $\delta 3.3-5 \mathrm{ppm}$ [15]. Meanwhile, the ${ }^{1} \mathrm{H}-\mathrm{NMR}$ spectrum of cellulose-L-methionine revealed the presence of new signals related to the L-methionine amino acid moieties substituted C-6 of cellulose, such as the signals at $\delta 2.06,2.51$, and $2.67 \mathrm{ppm}$ for $\mathrm{CH}_{3}, \mathrm{CH}_{2}$, and $\mathrm{CH}$, respectively. It is evident that the complete replacement of the tosyl group was confirmed by the disappearance of the signals ascribed to the tosyl group.

3.2.4. Scanning Electron Microscopy (SEM). Figure 4 displays the morphological structure of MCC (a), tosyl cellulose (b), and cellulose-L-methionine derivative (c). The SEM images of the surface of (a), (b), and (c) show clear differences between them. The MCC is mainly composed of platelet- like cellulose microfibrils, shaped into a spherical agglomeration. However, the surface structure of tosyl cellulose (b) is compact, the cellulose-L-methionine (c) had much greater porosity, and the surface roughness of cellulose derivative increased more than unmodified MCC. Interruption of the backbone of tosyl cellulose polymer can explain this observation as a result of reaction of the hydroxyl group $(-\mathrm{OH})$ of MCC with $p$-tosyl chloride and probably due to breaking of hydrogen bonds present in the MCC and interaction between the newly introduced hydrophobic phenyl groups. Thus, nucleophilic substitution reaction of tosyl cellulose with Lmethionine amino acid leads to very significant changes in the morphology of the unmodified MCC.

3.3. In Vitro Antibacterial Activity. The development of generations of new strains of bacteria is potentially harmful and stresses the importance of developing materials to fight human pandemics; for that, the natural antibacterial agent has been one of the hot topics in scientific research to develop 
TABLE 1: Minimal inhibitory concentration (MIC) of the celluloseL-methionine.

\begin{tabular}{|c|c|c|c|c|}
\hline \multirow[b]{2}{*}{ Samples } & \multicolumn{4}{|c|}{$\mathrm{MIC}(\mathrm{mg} / \mathrm{mL})$} \\
\hline & $\begin{array}{c}E . \\
\text { coli }\end{array}$ & $\begin{array}{c}P . \\
\text { aeruginosa }\end{array}$ & $\begin{array}{c}S . \\
\text { aureus }\end{array}$ & $\begin{array}{c}S . \\
\text { fasciens }\end{array}$ \\
\hline $\begin{array}{l}\text { Cellulose-L- } \\
\text { methionine }\end{array}$ & 10 & 20 & 20 & 5 \\
\hline Ampicillin & 12.5 & 25 & 12.5 & 6.25 \\
\hline Chloramphenicol & 6.25 & 6.25 & 12.5 & 12.5 \\
\hline
\end{tabular}

antibacterial agent from naturally abundant biopolymers such as cellulose and chitosan. It is expected in the field of biomedical and antibacterial films, cosmetics, textile industries, pharmaceutical, and other fields. To compare and analyze the antibacterial behavior contributed from cellulose-L-methionine and commercial antibiotics such as chloramphenicol and ampicillin, we have tested the cellulose-L-methionine against the bacteria: Escherichia coli, Pseudomonas aeruginosa, Staphylococcus aureus, and Streptococcus fasciens using the diffusion method disk for evaluating the applicability of cellulose-L-methionine product as an antibacterial agent [30,31]. Figure 5 summarizes the diameter of inhibition $(\mathrm{mm})$ values of cellulose-L-methionine and commercial antibiotics chloramphenicol and ampicillin. The minimal inhibitory concentration (MIC) values of the cellulose-L-methionine against the bacteria are presented in Table 1 . The cellulose-L-methionine product showed high antibacterial activity and different degrees of growth inhibition against the four bacteria tested; the maximum effect of the product tested was recorded against Streptococcus fasciens (diameter of inhibition $21.2 \mathrm{~mm}$ ), when compared with other bacteria, with MIC value of $5 \mathrm{mg} / \mathrm{mL}$. It is clear that there is a significant enhancement and a strong antibacterial activity associated with cellulose-L-methionine, as compared to commercial antibiotic. This biologic effect is due to the chemical structure and chemical functionality of celluloseL-methionine. No zone inhibition was observed with water. In our previous work, we have synthesized the celluloseacetanilide ether with different degrees of substitution (DS); it was found that the cellulose-acetanilide product was found to be more active against the chosen pathogenic bacteria strain Rhodococcus sp. GK1, and that the antibacterial activity of this product increased with DS [32]. Indeed, several studies have been focused on antibacterial properties of cellulose derivatives and proved effects against various bacterial strains [33-37]. Similarly, El-Sayed et al. [13] synthesized new water-soluble cellulose derivatives such as 4(celluloseamino) butyric acid and 2(celluloseamino) succinic acid; they have found that its cytotoxicity profile is negligible. The mechanism of antibacterial action of our compound synthesized is not attributable to one specific mechanism because there are several target sites in the bacterial cell such as the cell wall, cytoplasmic membrane and cytoplasm, leakage of cell contents, and coagulation of the cytoplasm; however, the structures of the bacterial outer envelope are more interesting as they differ between microorganisms. For example, the outer membrane of Gram-negative bacteria $[38,39]$ and the cell wall of mycobacteria [40] act as permeability barriers and are responsible for the intrinsic resistance of these microorganisms to antimicrobial compounds. A study is needed to understand the susceptibility of bacteria to our antimicrobial compounds; thus, anti-inflammatory, antifungal, antiparasitic, and anticancer activities are necessary, and some other types of Gram-negative and Gram-positive bacteria may possibly be tested by employing the same method. The literature gives a lot of interesting results on these topics $[29,41]$.

\section{Conclusion}

The tosyl cellulose with degree of substitution DS $=1$ was successfully synthesized by an esterification reaction of microcrystalline cellulose in $\mathrm{DMAc} / \mathrm{LiCl}(8 \%)$ solvent system in the presence of triethylamine (TEA) at $8^{\circ} \mathrm{C}$ for $24 \mathrm{~h}$. The nucleophilic displacement $\left(\mathrm{S}_{\mathrm{N}}\right)$ reaction of the tosyl group with L-methionine amino acid could be efficiently carried out leading to water-soluble methionine-substituted cellulose derivative. The characterization by means of NMR and FTIR spectroscopy, elemental analysis, and SEM indicates a uniform structure of the tosyl cellulose and cellulose-Lmethionine. The antibacterial test of cellulose-L-methionine shows significant activity against Escherichia coli, Pseudomonas aeruginosa, Staphylococcus aureus, and Streptococcus fasciens strains of bacteria. In our future research, we intend to focus on explaining the exact mechanism of cellulose-Lmethionine that induces bacterial cytotoxicity. This work encourages us to develop cellulose-based antibacterial materials for use in different biomedical and pharmaceutical applications.

\section{Data Availability}

The data used to support the findings of this study are available from the corresponding author upon request.

\section{Conflicts of Interest}

The authors declare that there is no conflict of interest.

\section{References}

[1] D. Klemm, B. Heublein, H. P. Fink, and A. Bohn, "Cellulose: fascinating biopolymer and sustainable raw material," Angewandte Chemie International Edition, vol. 44, no. 22, pp. 3358-3393, 2005.

[2] S. Kamel, N. Ali, K. Jahangir, S. M. Shah, and A. A. El-Gendy, "Pharmaceutical significance of cellulose: a review," Express Polymer Letters, vol. 2, no. 11, pp. 758-778, 2008.

[3] D. Klemm, B. Philipp, T. Heinze, U. Heinze, and W. Wagenknecht, Comprehensive Cellulose Chemistry. Volume 1: Fundamentals and Analytical Methods, Wiley-VCH Verlag, Weinheim, 1998.

[4] T. Heinze and T. Liebert, Polymer Science: A Comprehensive Reference, Elsevier B.V, Amsterdam, 2012.

[5] C. L. McCormick, P. A. Callais, and B. H. Hutchinson Jr., "Solution studies of cellulose in lithium chloride and N,Ndimethylacetamide," Macromolecules, vol. 18, no. 12, pp. 2394-2401, 1985. 
[6] R. P. Swatloski, S. K. Spear, J. D. Holbrey, and R. D. Rogers, "Dissolution of cellulose with ionic liquids," Journal of the American Chemical Society, vol. 124, no. 18, pp. 4974-4975, 2002.

[7] Q. Ren, J. Wu, J. Zhang, J. S. He, and M. L. Guo, "Synthesis of 1-allyl,3-methylimidazolium-based room-temperature ionic liquid and preliminary study of its dissolving cellulose," Acta Polymerica Sinica, vol. 1, pp. 448-451, 2003.

[8] L. El Hamdaoui, M. El Moussaouiti, and S. Gmouh, "Homogeneous esterification of cellulose in the mixture $\mathrm{N}$ butylpyridinium chloride/dimethylsulfoxide," International Journal of Polymer Science, vol. 2016, Article ID 1756971, 7 pages, 2016.

[9] S. Hokkanen, A. Hatnagar, and M. Sillanpää, "A review on modification methods to cellulose-based adsorbents to improve adsorption capacity," Water Research, vol. 91, pp. 156-173, 2016.

[10] S. Chenampulli, G. Unnikrishnan, S. Thomas, and S. S. Narine, "Novel ethylene diamine functionalised nanocellulose/poly(ethylene-co-acrylic acid) composites for biomedical applications," Cellulose, vol. 26, no. 3, pp. 1795-1809, 2019.

[11] K. Heise, G. Delepierre, W. T. K. Alistair et al., "Chemical modification of reducing end-groups in cellulose nanocrystals," Angewandte Chemie, vol. 60, no. 1, pp. 66-87, 2021.

[12] A. Pfeifer, M. Gericke, and T. Heinze, "Synthesis and characterization of novel water-soluble 6-deoxy-6-(2-amino-2(hydroxymethyl) propane-1,3-diol)cellulose derivatives," Advanced Industrial and Engineering Polymer Research, vol. 3, no. 2, pp. 77-82, 2020.

[13] N. S. El-Sayed, M. El-Sakhawy, P. Hesemann, N. Brun, and S. Kamel, "Rational design of novel water-soluble ampholytic cellulose derivatives," International Journal of Biological Macromolecules, vol. 114, pp. 363-372, 2018.

[14] S. Schmidt, T. Liebert, and T. Heinze, "Synthesis of soluble cellulose tosylates in an eco-friendly medium," Green Chemistry, vol. 16, no. 4, pp. 1941-1946, 2014.

[15] T. Heinze, K. Rahn, M. Jaspers, and H. Berghmans, “p-Toluenesulfonyl esters in cellulose modifications: acylation of remaining hydroxyl groups," Macromolecular Chemistry and Physics, vol. 197, no. 12, pp. 4207-4224, 1996.

[16] L. El Hamdaoui, A. Es-said, M. El Marouani et al., "Tosylation optimization, characterization and pyrolysis kinetics of cellulose tosylate," ChemistrySelect, vol. 5, no. 26, pp. 7695-7703, 2020 .

[17] J. Zhang, J. Yuan, Y. Yuan, J. Shen, and S. Lin, "Chemical modification of cellulose membranes with sulfo ammonium zwitterionic vinyl monomer to improve hemocompatibility," Colloids and Surfaces B: Biointerfaces, vol. 30, no. 3, pp. 249257, 2003.

[18] X. Sui, J. Yuan, M. Zhou et al., "Synthesis of cellulose-graftpoly(N,N-dimethylamino-2-ethyl methacrylate) copolymers via homogeneous ATRP and their aggregates in aqueous media," Biomacromolecules, vol. 9, no. 10, pp. 2615-2620, 2008.

[19] U. D. Hemraz, A. K. Campbell, J. S. Burdick, K. Ckless, Y. Boluk, and R. Sunasee, "Cationic poly (2-aminoethylmethacrylate) and poly (N-2-aminoethylmethacrylamide) modified cellulose nanocrystals: synthesis, characterization, and cytotoxicity," Biomacromolecules, vol. 16, pp. 319-325, 2014.

[20] H. Kono and R. Kusumoto, "Preparation, structural characterization, and flocculation ability of amphoteric cellulose," Reactive and Functional Polymers, vol. 82, pp. 111-119, 2014.
[21] T. Groth and W. Wagenknecht, "Anticoagulant potential of regioselective derivatized cellulose," Biomaterials, vol. 22, no. 20, pp. 2719-2729, 2001.

[22] C. Liu and H. Baumann, "Exclusive and complete introduction of amino groups and their $\mathrm{N}$-sulfo and $\mathrm{N}$-carboxymethyl groups into the 6-position of cellulose without the use of protecting groups," Carbohydrate Research, vol. 337, no. 14, pp. 1297-1307, 2002.

[23] M. N. El-Bohy, Y. K. Abdel-Monem, K. A. Rabie et al., "Grafting of arginine and glutamic acid onto cellulose for enhanced uranyl sorption," Cellulose, vol. 24, no. 3, pp. 1427-1443, 2017.

[24] T. Heinze, M. Siebert, P. Berlin, and A. Koschella, "Biofunctional materials based on amino cellulose derivatives - a nanobiotechnological concept," Macromolecular Bioscience, vol. 16, no. 1, pp. 10-42, 2016.

[25] P. Berlin, D. Klemm, A. Jung, H. Liebegott, R. Rieseler, and J. Tiller, "Film-forming aminocellulose derivatives as enzyme-compatible support matrices for biosensor developments," Cellulose, vol. 10, no. 4, pp. 343-367, 2003.

[26] N. S. El-Sayed, M. E. Abd El-Aziz, S. Kamel, and G. Turky, "Synthesis and characterization of polyaniline/tosylcellulose stearate composites as promising semiconducting materials," Synthetic Metals, vol. 236, pp. 44-53, 2018.

[27] K. Rahn, M. Diamantoglou, D. Klemm, H. Berghmans, and T. Heinze, "Homogeneous synthesis of cellulose ptoluenesulfonates in $\mathrm{N}, \mathrm{N}$-dimethyl-acetamide/LiCl solvent system," Die Angewandte Makromolekulare Chemie, vol. 238, no. 1, pp. 143-163, 1996.

[28] S. Y. Daniyan and H. B. Mahammad, "Evaluation of the antimicrobial activities and phytochemical properties of extracts of Tamarindus indica against some diseases causing bacteria," African Journal of Biotechnology, vol. 7, pp. 2451-2453, 2008.

[29] D. Alderman and P. Smith, "Development of draft protocols of standard reference methods for antimicrobial agent susceptibility testing of bacteria associated with fish diseases," Aquaculture, vol. 196, no. 3-4, pp. 211-243, 2001.

[30] Y. N. Mabkhot, F. Alatibi, N. N. E. El-Sayed, N. A. Kheder, and S. S. Al-Showiman, "Synthesis and structure-activity relationship of some new thiophene-based heterocycles as potential antimicrobial agents," Molecules, vol. 21, no. 8, p. 1036, 2016.

[31] K. Hoffmann, J. Wiśniewska, A. Wojtczak et al., "Rational design of dicarboxylato platinum (II) complexes with purinemimetic ligands as novel anticancer agents," Journal of Inorganic Biochemistry, vol. 172, pp. 34-45, 2017.

[32] L. El Hamdaoui, A. Talbaoui, and M. El Moussaouiti, "Synthesis and characterization of cellulose acetanilide ether and its antibacterial activity," Polymer Bulletin, vol. 75, pp. 24012413, 2017.

[33] X. William, G. Guangzheng, and K. John, "Synthesis of antibacterial cellulose materials using a clickable quaternary ammonium compound," Cellulose, vol. 20, pp. 1187-1199, 2013.

[34] A. Hou, M. Zhou, and X. Wang, "Preparation and characterization of durable antibacterial cellulose biomaterials modified with triazine derivatives," Carbohydrate Polymers, vol. 75, no. 2, pp. 328-332, 2009.

[35] J. Wu, N. Zhao, X. Zhang, and J. Xu, "Cellulose/silver nanoparticles composite microspheres: ecofriendly synthesis and catalytic application," Cellulose, vol. 19, no. 4, pp. 1239-1249, 2012.

[36] G. Yang, J. Xie, Y. Deng, Y. Bian, and F. Hong, "Hydrothermal synthesis of bacterial cellulose/AgNPs composite: a green 
route for antibacterial application," Carbohydrate Polymers, vol. 87, no. 4, pp. 2482-2487, 2012.

[37] X. Yongjian, S. Yun, L. Feng, and D. Lei, “A novel and green cellulose-based Schiff base-Cu (II) complex and its excellent antibacterial activity," Carbohydrate Polymers, vol. 230, p. 115671, 2020.

[38] H. Nikaido and M. Vaara, "Molecular basis of bacterial outer membrane permeability," Microbiological Review, vol. 49, no. 1, pp. 1-32, 1985.

[39] P. Gilbert, D. Pemberton, and D. E. Wilkinson, "Barrier properties of the Gram-negative cell envelope towards high molecular weight polyhexamethylene biguanides," Journal of Applied Microbiology, vol. 69, pp. 585-592, 1990.

[40] J. Trias and J. Benz, "Permeability of the cell wall of Mycobacterium smegmatis," Molecular Microbiology, vol. 14, no. 2, pp. 283-290, 1994.

[41] L. Zhanga, P. Yana, Y. Lia, X. Heb, Y. Daib, and Z. Tana, "Preparation and antibacterial activity of a cellulose-based Schiff base derived from dialdehyde cellulose and L-lysine," Industrial Crops and Products, vol. 145, article 112126, 2020. 